\title{
UV curing of a liquid based bismaleimide-containing polymer system
}

\author{
S. L. Fan ${ }^{1,2}$, F. Y. C. Boey2, M. J. M. Abadie ${ }^{1,2^{*}}$ \\ ${ }^{1}$ Laboratory of Polymer Science \& Advanced Organic Materials - LEMP-MAO, CC 021, Université Montpellier 2, \\ Place E.Bataillon, 34095 Montpellier, France \\ ${ }^{2}$ School of Materials Science and Engineering, Nanyang Technological University, 50 Nanyang Avenue, 639798 \\ Singapore
}

Received 2 April 2007; accepted in revised form 12 May 2007

\begin{abstract}
A new liquid formulation of commercial bismaleimide and n-acryloylmorpholine was prepared that could be UV cured as an alternative to traditional thermal cure methods presently used for BMI in the industry. UV curing was shown to be an efficient method which promoted the reaction rate significantly and was able to achieve this at low temperatures $\left(30-50^{\circ} \mathrm{C}\right)$. A free radical polymerization approach has been used to explain the cure mechanism and cure kinetics, using data elucidated from the DPC and FTIR. The cured thin film was shown to achieve very high thermal stability $\left(\sim 400^{\circ} \mathrm{C}\right)$, with the BMI shown to retard the thermal degradation temperature and rate.
\end{abstract}

Keywords: thermosetting resins, bismaleimide, UV curing

\section{Introduction}

Bismaleimide resins are well-known for their high performance since 1960s. As an ideal thermal resistant resins filling in the margin between epoxies and polyimides, bismaleimide also possesses some other remarkable properties such as low moisture absorption, highly crosslinked structures, high chemical resistance, high mechanical stability, etc. These advantages make bismaleimide applied widely in adhesive, packaging and aerospace industry. However two shortcomings, namely brittleness and poor process ability, have limit commercial bismaleimide for further application. These two drawbacks are due to the high density of crosslink and high crystalline content. Many investigations have been done or are focused on improving its properties in order to increase the application [1-7]. Other papers have shown the cure mechanism and

*Corresponding author, e-mail: abadie@ @univ-montp2.fr

(C) BME-PT and GTE kinetics for BMI and modified BMI systems during thermal curing [2, 8-10].

Several methods have been used to improve the processibility of bismaleimide [11]. Critical to this is the ability to process BMI into a liquid form with similar behavior to epoxy, for example [12]. This is done by formulations which include synthesizing of new liquid BMI resins through modification of the BMI molecule with other molecules and copolymers, or dissolving BMI into reactive organic diluents. Currently, bismaleimide 36 carbon cycloaliphatic branched structure (Q-Bond) [13] and polypropylenoxide-bismaleimide (MIA) [14] are two liquid BMI resins available, though they have very high viscosity and high cost. Attempts have been made to modify BMI by other molecules and copolymers to improve the processibility [15-16]. Typically, Cyanate ester [17] and diallyl bisphenol A [18] are used as copolymers to improve the processability. Dissolving conven- 
tional BMI resins into reactive organic diluents has proven difficult because of its low solubility and the requirement for high temperature thermal curing.

The use of radiation curing has been shown to give faster cure rates. This includes the use of microwave curing [19-21], UV [22-23] and ebeam [24-26] for curing of thin film thermosetting polymers have been shown to give practical and effective advantages [19-21].

$\mathrm{N}$-acryloylmorpholine shows a capability to dissolve traditional BMI with high concentration. A liquid formulation which can be radiation cured enables it to be processed in more practical process methods, such as resin transfer molding (RTM) [3]. In addition, these cured products typically have better mechanical properties, especially improvement in its brittleness.

Although thermal curing is currently the most widely used method for curing BMI, it is also relatively low in efficiency and can have high cost. More recently, UV curing has been investigated by researchers such as Decker et al. [13]. The new curing method possesses many advantages, such as room temperature cure, high reaction rate, energy efficiency, low volatility of organic compound and easy control. The UV cure mechanism and kinetics for homo- and copolymerization of BMI, and their final cure properties were reported [2, 27, 28].

This paper reports on the study of a new liquid formulation for a BMI/n-acryloylmorpholine polymer system for UV curing. The photo polymerization behavior was investigated in situ by using a Differential Photo Calorimeter. The parameters for the cure kinetics were elucidated and the cure mechanism was proposed. The thermal stability of the material as a thin film was also studied.

\section{Experimental}

\subsection{Materials}

1,1'-(methylenedi-4,1-phenylene)-bismaleimide (BMI) was obtained from Aldrich Chemicals; nacryloylmorpholine (AMP) was purchased from Polyscience, Inc. IRGACURE1000 was obtained from the Ciba Chemical Company and was used as photoinitiator. All chemicals were used without further purification. The structures of the chemicals are given in Figure 1.

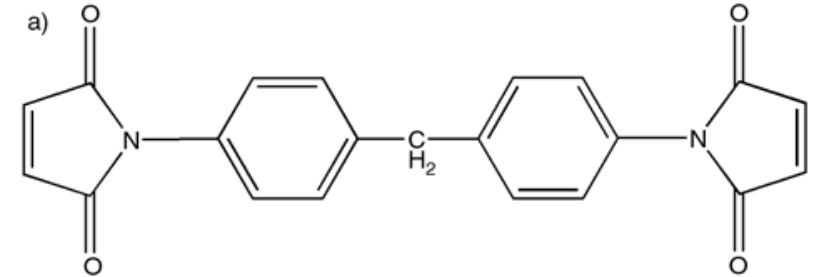

b)
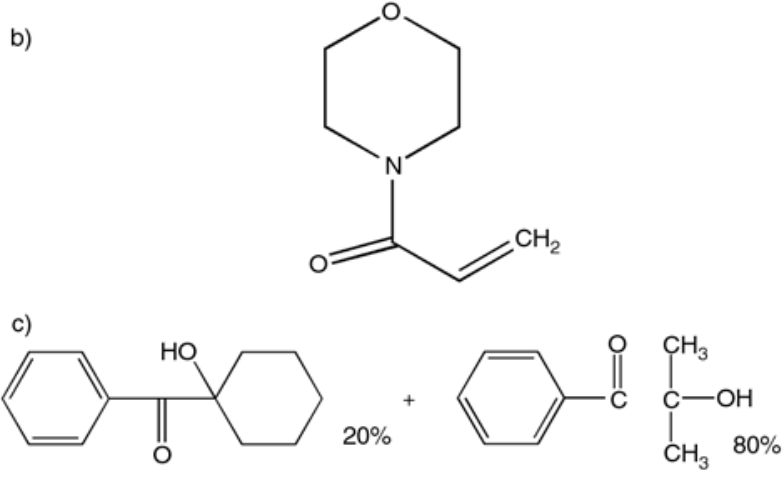

Figure 1. The chemical structures. a) 1,1'-(methylenedi4,1-phenylene)-bismaleimide (BMI), b) N-Acryloylmorpholine, c) IRGACURE1000

\subsection{Methods}

\subsubsection{Preparation of liquid formulation}

The solubility of BMI in AMP was tested and the highest solubility is about 1:3 by molar ratio of carbon double bond (BMI:AMP) at $110^{\circ} \mathrm{C}$. There was a critical point at $70^{\circ} \mathrm{C}$ where the solubility had a sudden increase. The liquid formulation was prepared in a brown bottle with magnetic stirring at $70^{\circ} \mathrm{C}$. BMI powders dissolved and brown transparent solution was formed. A series of liquid formulations were prepared and the components are listed in Table 1.

Table 1. The components of liquid formulations

\begin{tabular}{|c|c|c|c|}
\hline System & $\begin{array}{c}\text { AMP } \\
\text { [\% by weight] }\end{array}$ & $\begin{array}{c}\text { BMI } \\
{[\%]}\end{array}$ & $\begin{array}{c}\text { Photoinitiator } \\
{[\%]}\end{array}$ \\
\hline 1 & 100 & 0 & 3 \\
\hline 2 & 90 & 10 & 0 \\
\hline 3 & 90 & 10 & 3 \\
\hline 4 & 80 & 20 & 3 \\
\hline
\end{tabular}

\subsubsection{UV irradiation}

The photopolymerization was conducted by using a Differential Photo Calorimeter (DPC) which recorded the real-time exothermal heat of reaction and calculated the kinetics of reaction. The intensity of the UV source was fixed at $18.5 \mathrm{~mW} / \mathrm{cm}^{2}$. About $1 \mathrm{mg}$ of the sample was transferred into an 
aluminum pan and then placed into the DPC cell. A polyethyleneterephtalate film was used to cover the sample in order to prevent the oxygen diffusion and planarize the liquid film. A fully cured BMI/AMP film was used as reference. The sample was exposed isothermally from 5 to 10 minutes at different temperatures from 30 to $90^{\circ} \mathrm{C}$ with purge nitrogen.

\subsubsection{Characterization}

The FTIR was employed to monitor changes in $\mathrm{C}=\mathrm{C}$ absorption in order to ascertain the formation of sequential product. The experiments were conducted in absorption mode at $4 \mathrm{~cm}^{-1}$ resolution with 32 scans per spectrum. A Spectrum GX System FTIR spectrometer, Perkin Elmer Instruments, was used.

The Differential scanning calorimetry (DSC) was performed at a heating rate of $10^{\circ} \mathrm{C} / \mathrm{min}$ using a DSC 2920, TA Instruments Inc, to obtain the cure or thermal behavior information of these systems. The Glass transition temperature $\left(T_{g}\right)$ was measured by a Modulated DSC system. Thermal degradation was investigated by using the TGA in a nitrogen atmosphere with a heating rate of $10^{\circ} \mathrm{C} / \mathrm{min}$ till $700^{\circ} \mathrm{C}$.

\section{Results and discussions}

The liquid formulations of bismaleimide/n-acryloylmorpholine with low viscosity have been prepared. Here we report the investigation of UV curing behaviors and the characterization of thermal properties.

Figure 2 is the DPC plot of four systems: AMP with photoinitiator, AMP/BMI without photoinitiator and AMP/BMI with photoinitiator (different concentration). An obvious exothermal peak was observed in each curve except the one of AMP/BMI without photoinitiator. The UV curing polymerization proceeded very fast and finished in several minutes, proving that this technique is more

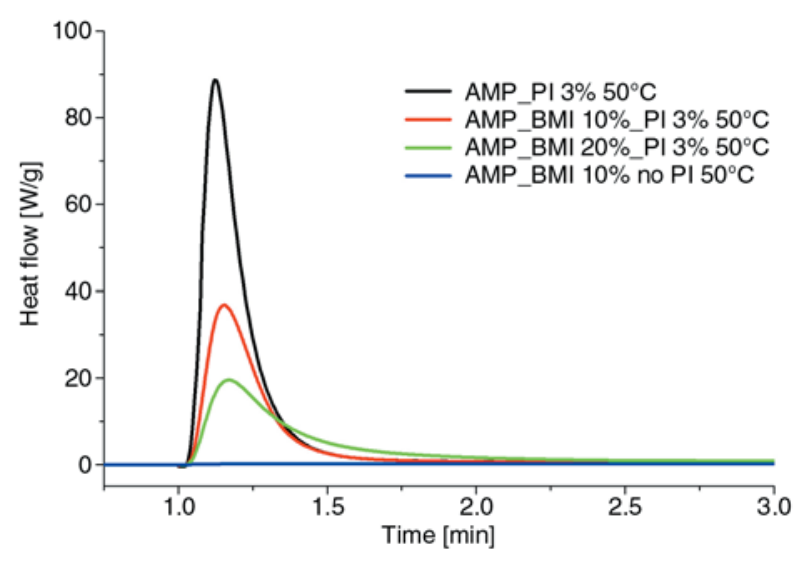

Figure 2. DPC plot of different systems

efficient than conventional thermosetting method. BMI was reported to have a capability to initiate a photopolymerization in some systems via accepterdonor mechanism $[2,27,28]$, but for this study, a repetition of this capability could not be achieved. AMP resins polymerized very fast and the reaction completed within second. Christian Pichot indicated that the conversion could achieve nearly $100 \%$ for homopolymerization [29]. However, the exothermal peak drops down gradually with increasing BMI content, which indicated that bismaleimide has a negative influence on the photopolymerization behavior. This could be because BMI increases the viscosity of the liquid formulation and forms crosslink structure in the film. Table 2 lists some reaction parameters which also disclose the effect from bismaleimide. For example, the induction time expends from $1.7 \mathrm{~s}$ to $4.1 \mathrm{~s}$ at $50^{\circ} \mathrm{C}$ with an increase of $\mathrm{BMI}$, while the enthalpy decreases from $511.7 \mathrm{~J} / \mathrm{g}$ to $384.8 \mathrm{~J} / \mathrm{g}$.

Figure 3 describes the effect of the ambient temperature on the effectiveness of photopolymerization. According to the enthalpy value (Table 2), the highest conversion was achieved at $50^{\circ} \mathrm{C}$, and then dropped with higher temperature. This could be because of the competition between propagation and termination in free-radical mechanism. Another explanation is that some of the AMP resins evaporated during UV curing, so the enthalpy only

Table 2. The kinetics data of UV polymerization

\begin{tabular}{|c|c|c|c|c|c|c|c|c|c|c|c|c|}
\hline & \multicolumn{4}{|c|}{ AMP } & \multicolumn{4}{c|}{ AMP + 10\% BMI } & \multicolumn{4}{c|}{ AMP + 20\% BMI } \\
\hline $\boldsymbol{T}\left[{ }^{\circ} \mathbf{C}\right]$ & $\mathbf{\Delta H}$ & $\mathbf{M P}$ & $\mathbf{R P}$ & $\mathbf{I T}$ & $\boldsymbol{\Delta H}$ & $\mathbf{M P}$ & $\mathbf{R P}$ & $\mathbf{I T}$ & $\Delta \mathbf{H}$ & $\mathbf{M P}$ & $\mathbf{R P}$ & $\mathbf{I T}$ \\
\hline 30 & 474.4 & 3.6 & 27.1 & 1.6 & 335.6 & 8.0 & 24.0 & 3.4 & 310.9 & 10.8 & 20.0 & 4.7 \\
\hline 50 & 511.7 & 3.8 & 24.8 & 1.7 & 405.1 & 8.0 & 29.6 & 3.5 & 384.8 & 10.0 & 22.5 & 4.1 \\
\hline 70 & 503.6 & 4.0 & 31.3 & 1.6 & 405.6 & 9.2 & 30.7 & 3.7 & 355.4 & 11.4 & 23.8 & 4.1 \\
\hline 90 & 489.0 & 4.0 & 30.5 & 1.5 & 379.2 & 7.6 & 24.6 & 2.9 & 235.8 & 10.4 & 18.9 & 3,8 \\
\hline
\end{tabular}

$\Delta H$ : enthalpy [J/g]; MP: maximum peak [s]; RP: reaction at peak [\%]; IT: induction time [s] 


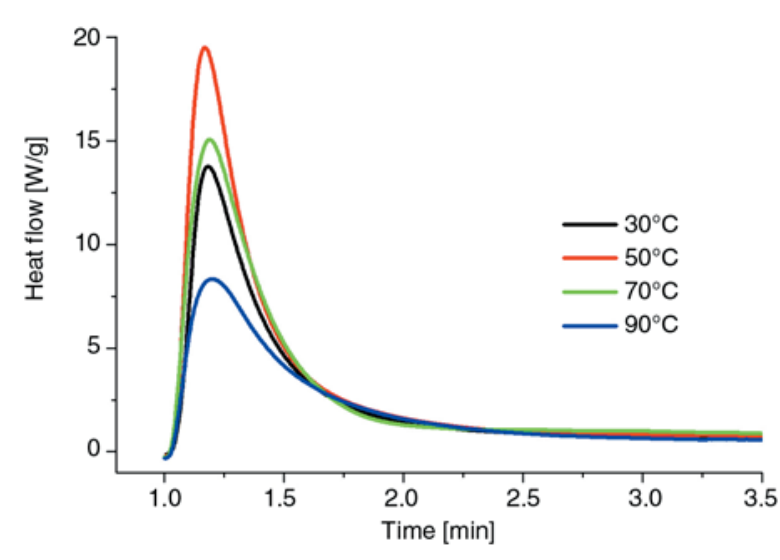

Figure 3. The temperature influence on UV curing. DPC plot of AMP $/ 20 \% \mathrm{BMI} / 3 \% \mathrm{PI}, 30-90^{\circ} \mathrm{C}$

came from the remaining reactants. It is also possible that because of the relevant high concentration of photoinitiator, a thin film forms on the surface of sample, which absorbs much of UV light and acts as a shield to prevent the UV light penetrating into the bulk of liquid formulation, then the reaction stops. Anyway, this can be avoided by decreasing the concentration of photoinitiator and the thickness of the sample. The induction time (1\% conversion) decreased with the rising of temperature, which is reasonable because resins become more active and easier to react at higher temperature.

\subsection{Kinetics of photopolymerization}

Cure kinetics is typically used to understand the cure reaction process quantitatively [30]. The results of the DPC gave the real-time exothermal heat which could then be used to calculate the kinetics of reaction. The conversion degree is calculated by Equation (1):

$a=\frac{H_{t}}{H_{\text {total }}} \cdot 100[\%]$

where $H_{t}$ is the sum of exothermal heat at time $t$, $H_{\text {total }}$ is the total reaction heat (enthalpy), $a$ is the conversion degree. The theoretical enthalpy of acrylate polymerization is $80.5 \mathrm{~kJ} / \mathrm{mol}$, [31] which is a little higher than the one of AMP resins, $72.3 \mathrm{~kJ} / \mathrm{mol}$. Our analysis and calculation are based on the assumption that the system reacted completely at $50^{\circ} \mathrm{C}$ because it's hard to get the $H_{\text {total }}$ for $100 \%$ conversion. Anyway, $a$ and $H_{t}$ have a linear relationship, so the curve keeps the same shape no matter how much the ideal $H_{\text {total }}$ is.
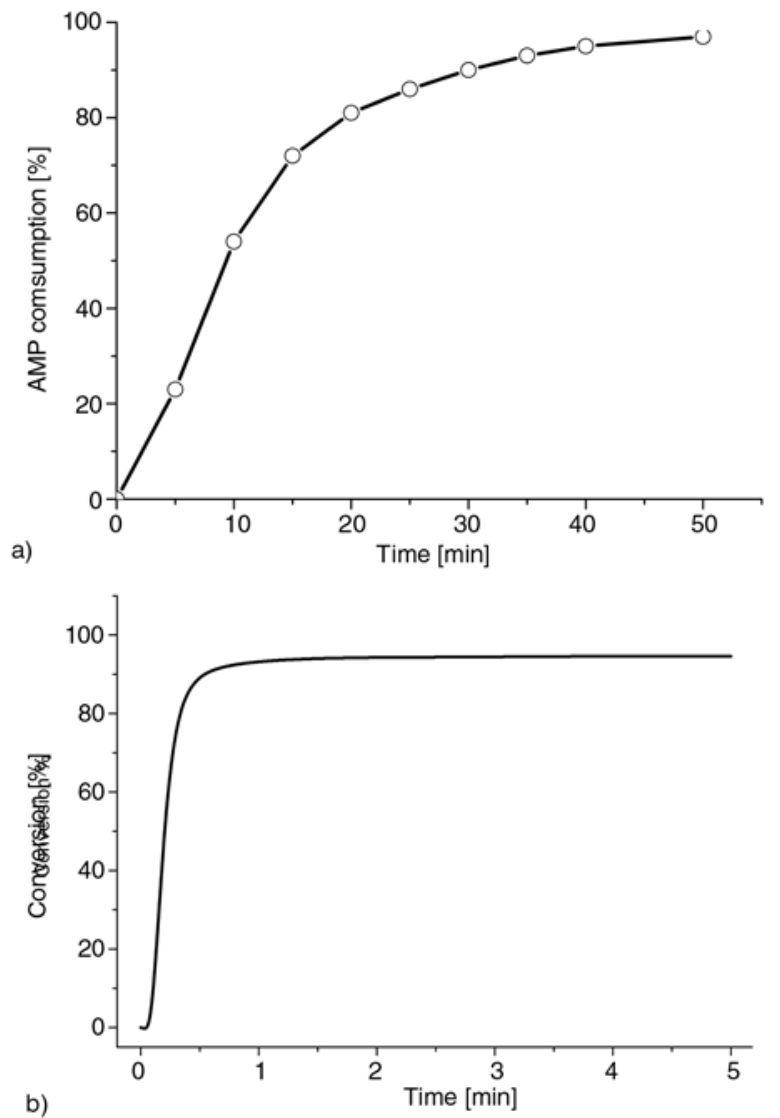

Figure 4. The compare of conversion $v s$. time for AMP homopolymerization in bulk solution and under UV curing. a) in 1,4-dioxane solution [29], b) by UV irradiation

For AMP/BMI system, homo- and copolymerization occurred simultaneously, so the calculation yielded the conversion of the overall reaction. Figure 4 compares the conversion of AMP polymerization in bulk for thermal curing to the conversion for a thin film by UV curing. The higher final percentage conversion and faster polymerization rate obtained for the latter demonstrate that the photoinitiated radical method is more efficient than for thermal curing.

The reaction rate can be calculated by Equation (2):

$\frac{\mathrm{d} a}{\mathrm{~d} t}=\frac{\Delta H_{t}}{\Delta t}$

Again, the calculation is for the overall reaction rate. Figure 5 plots the derivatives of the conversion versus time. The curve is typical for an autocatalytic kinetics type reaction. The results also show that high temperature has a negative effect to the reaction rate. Freddy also reported the kinetics of BMI with an organic reactant, but in thermal curing mechanism [32]. In his paper, the reaction fol- 


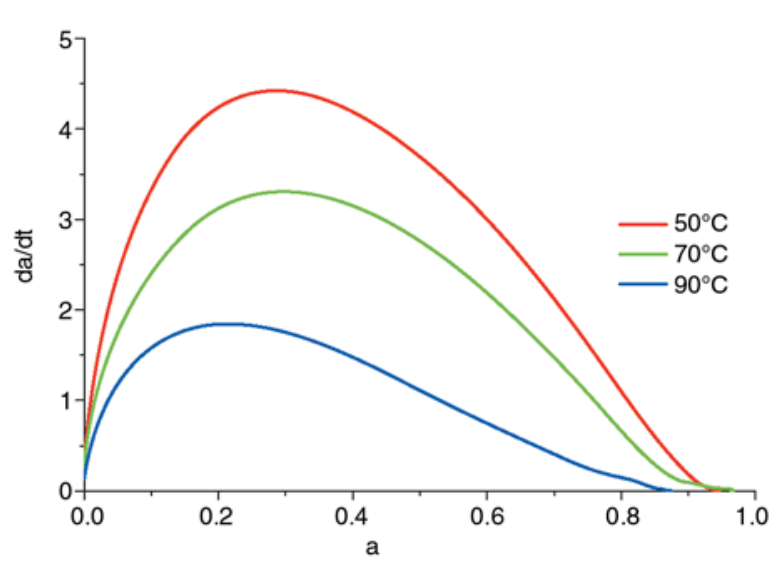

Figure 5. The overall reaction rate versus conversion of $\mathrm{AMP} / 10 \% \mathrm{BMI} / 3 \% \mathrm{PI}$ system

lowed the nth order model and the highest reaction rate is about $0.2 \mathrm{~min}^{-1}$, much slower than the one of UV curing.

An autocatalytic kinetics model can be described by Equation (3):

$$
\frac{\mathrm{d} a}{\mathrm{~d} t}=k a^{m}(1-a)^{n}
$$

where $\mathrm{d} a / \mathrm{d} t$ is the polymerization rate, $a$ is the fraction of reactant converted, $k$ is the Arrhenius-type reaction rate coefficient, $m$ is the order of the initiation reaction, and $n$ is the order of the propagation reaction. Empirically, $n$ is assumed to be similar in value for different cure temperatures, and fixed to $1.5, m$ can be calculated. The kinetics parameters are listed in Table 3 . These values are coincident with the analysis of DPC plot (Figures 2 and 3).

The rate coefficient, $k$, which is temperature dependent, can be used to calculate the activation energy of the reaction (Equation (4)).

$k=A \exp \left(-\frac{E_{a}}{R T}\right)$

where $E_{a}$ is the overall activation energy, $A$ is the overall frequency factor, $R$ is the ideal gas constant, and $T$ is the absolute temperature in Kelvin. When the sample is cured isothermally, if the Arrhenius relation is obeyed, the activation energy and fre-

Table 3. Lists of the kinetics parameters

\begin{tabular}{|c|c|c|c|c|}
\hline \multirow{2}{*}{} & \multicolumn{2}{|c|}{ AMP-10\%BMI } & \multicolumn{2}{c|}{ AMP-20\% BMI } \\
\cline { 2 - 5 } & $\mathbf{m}$ & $\mathbf{k}$ & $\mathbf{~}$ & $\mathbf{k}$ \\
\hline 30 & 0.479 & 11.7 & 0.332 & 5.83 \\
\hline 50 & 0.675 & 21.8 & 0.364 & 7.04 \\
\hline 70 & 0.661 & 17.8 & 0.418 & 6.55 \\
\hline 90 & 0.386 & 10.0 & 0.249 & 4.03 \\
\hline
\end{tabular}

quency factor can be determined from the slope and intercept, respectively, of the best-line fit of Arrhenius plot by $\ln (k)$ versus $1 / T$ (Equation (5)).

$$
\ln (k)=\ln (A)-\frac{E_{a}}{R T}
$$

The calculated values of $E_{a}$ and $A$ are shown in Table 4. Normally an increase in the speed of the reaction should be reflected in an increase in the collision factor. In our case, the calculated $E_{a}$ and $A$ are coincident to the general conclusion. Boey et al studied the kinetics of thermal curing of BMI and modified BMI, the activation energy is about $95 \mathrm{~J} / \mathrm{g}$, [32] which is a little more than the one of UV curing, $64.6 \mathrm{~J} / \mathrm{g}$.

Table 4. The activation energy and frequency factor for AMP/BMI systems

\begin{tabular}{|l|c|c|}
\hline & AMP-10\% BMI & AMP-20\% BMI \\
\hline$E_{a}[\mathrm{~kJ} / \mathrm{mol}]$ & $9.4 \pm 0.5$ & $2.6 \pm 0.1$ \\
\hline$A\left[\mathrm{~min}^{-1}\right]$ & 557.7 & 17.2 \\
\hline
\end{tabular}

\subsection{The mechanism of UV curing}

$\mathrm{N}$-acryloylmorpholine, which contains the acrylate function group, when cured using UV, follows a photo induced free radical polymerization mechanism [32]. Figure 6 shows a hypothesis structure of the AMP-BMI copolymer. The functionality of BMI $(f=2)$ would have made the film into an effectively 3-D network structure. The microstructure arrangement of the polymer phases of AMP and BMI is not clear. AMP and BMI are not in stoichiometric equilibrium because of the limited solubility of the latter. The final products may consist of homopolymerization of AMP, homopolymerization of BMI and copolymer of AMP and BMI, plus other side products.

The possible changes in the chemical bonds during the cure reaction have been analyzed using the FTIR method. The results in Figure 7 show the IR spectra of the monomers and cured polymers. The peaks at 790.7 and $950.7 \mathrm{~cm}^{-1}$, which represent the $\mathrm{C}=\mathrm{C}$ bond in AMP, have disappeared after polymerization. The strong absorption at $1234.2 \mathrm{~cm}^{-1}$ is identified as the $\mathrm{C}-\mathrm{N}-\mathrm{C}$ stretching vibration, weakened after polymerization. The absorption at $1610 \mathrm{~cm}^{-1}$, representing the $\mathrm{C}=\mathrm{C}$ stretching vibration has disappeared after irradiation. The absorptions at $692.3 \mathrm{~cm}^{-1}$ (C-H out-of-plane deformation 


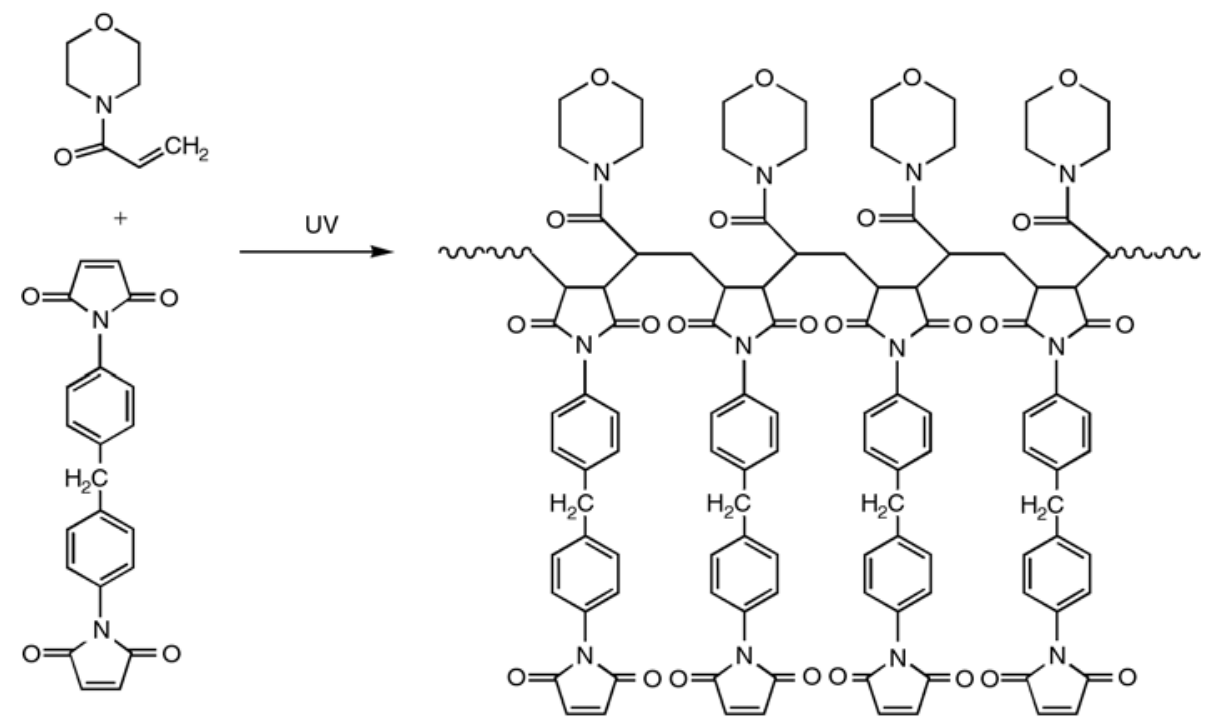

Figure 6. Scheme of co-polymerization of AMP-BMI

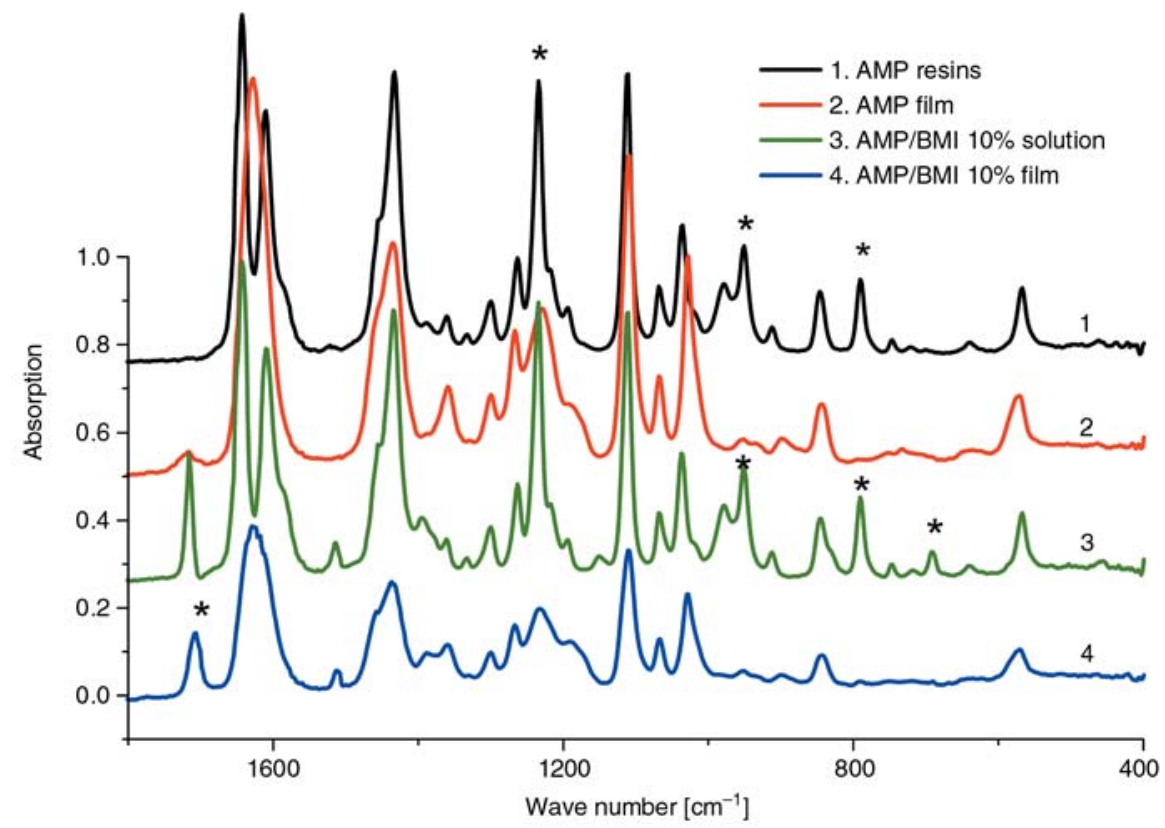

Figure 7. FTIR spectra of AMP-BMI systems: 1) AMP resins; 2) AMP films; 3) AMP/BMI 10\% solution; 4) AMP/BMI $10 \%$ film

vibration), $1394.3 \mathrm{~cm}^{-1}$ ( $\mathrm{C}=\mathrm{C}$ stretching vibration), $1513.9 \mathrm{~cm}^{-1}$ (maleimide) are characteristic for bismaleimide. The absorption at $692.3 \mathrm{~cm}^{-1}$ is typically used to probe the concentration of BMI quantitatively and qualitatively. The peak has disappeared after irradiation, indicating that most of the BMI has been polymerized.

\subsection{Thermal stability of AMP-BMI systems}

Post curing process was conducted by using DSC with nitrogen purge to increase the conversion degree and to observe the performance of raw materials and product at high temperature. Figure 8 and Figure 9 compare the behaviors of the uncured polymer and the UV cured films. In Figure 8, it is seen that pure AMP resins started to polymerize by thermosetting at about $140^{\circ} \mathrm{C}$ and reached maximum rate at $170^{\circ} \mathrm{C}$. It is also seen that by adding $10 \% \mathrm{BMI}$, the thermal cure peak is shifted to the right by about $30^{\circ} \mathrm{C}$. This perhaps comes from the pre-reaction between AMP and BMI in the liquid formulation. The exothermic heat of thermosetting curing was calculated by integrating the curve of the exothermic peak in Figure 8, which is about $350 \mathrm{~J} / \mathrm{g}$, less than UV curing ( $500 \mathrm{~J} / \mathrm{g}$, in Table 2$)$. The small peak in DSC plot of AMP/BMI10\% 


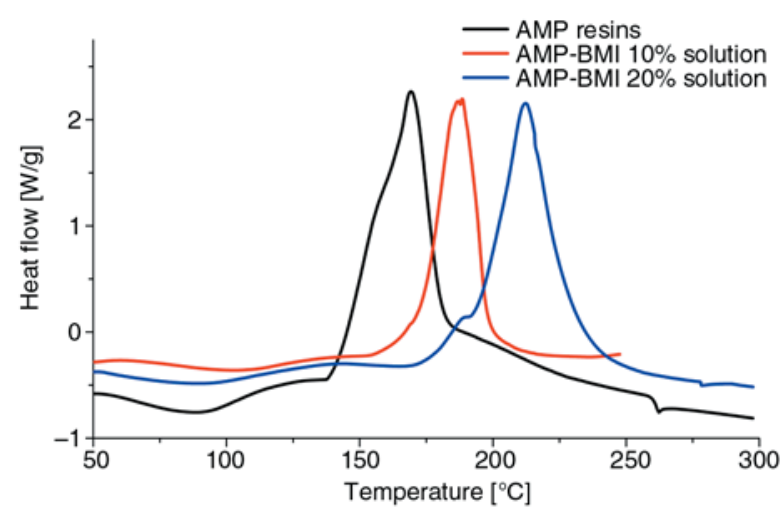

Figure 8. The DSC plot of liquid formulations of AMP/BMI systems

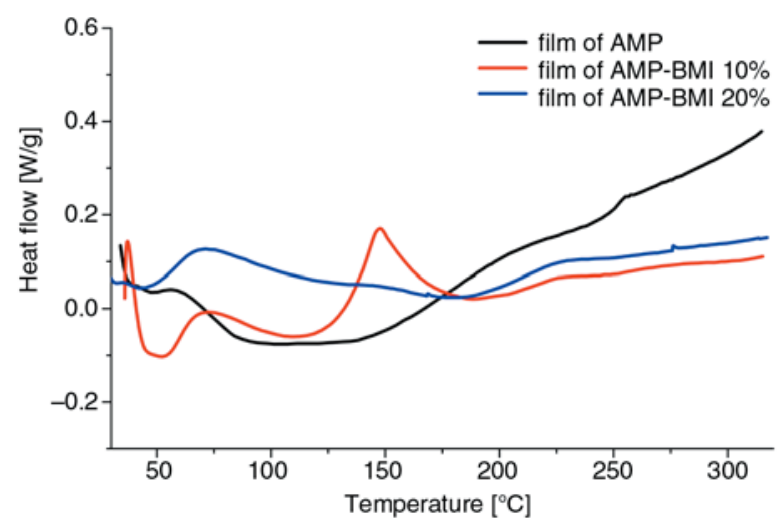

Figure 9. The post cure DSC plot after UV irradiation

cured film seen in Figure 9 is probably due to residual unreacted AMP or BMI resins.

\subsection{Thermal degradation of AMP-BMI systems}

The thermal degradation was investigated by using TGA. The plot is shown in Figure 10. Table 5 lists the temperatures for weight loss of 5\% $\left(T_{5 \%}\right)$, the temperatures at maximum weight loss rate $\left(T_{\max }\right)$, maximum weight loss rate $(R)$ and percentage char yield at $700^{\circ} \mathrm{C}\left(Y_{c}\right)$, to analyze the thermal stability. The addition of BMI decreased the conversion degree and also resulted in the production of oligomers in the process, which impaired the thermal stability of the polymer, resulting in a lower degradation temperature (comparing the $T_{5} \%$ values in Figure 10). Figure 11 plots the derivative of the $\mathrm{Y}$-axis values in Figure 10. The resulting lot shows that addition of BMI clearly decreased the degradation rate, which is perhaps due to the crosslinking network structure in the film which limited the diffusion rate of broken segments, and also due to the high thermal stability of BMI itself.

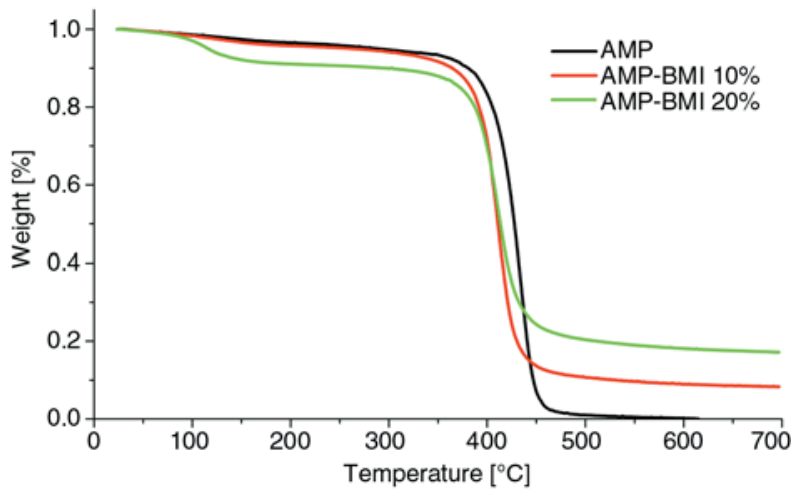

Figure 10. The TGA plot of AMP and AMP-BMI systems. $10^{\circ} \mathrm{C} / \mathrm{min}$

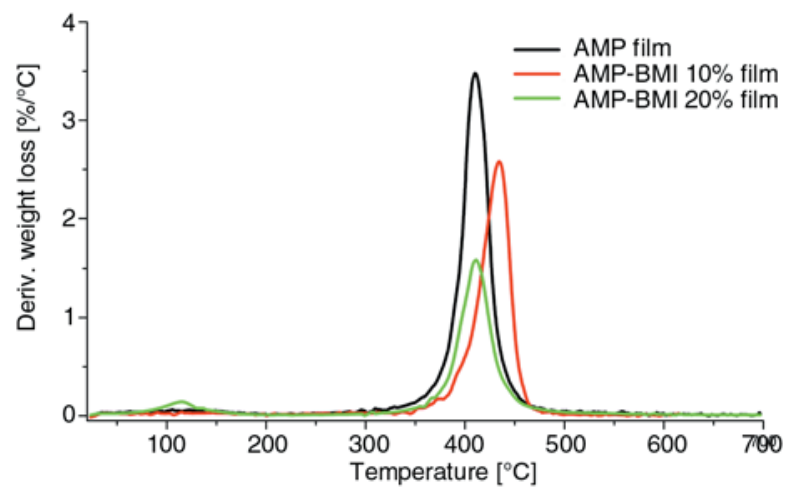

Figure 11. The derivation of TGA plot: AMP and AMPBMI systems

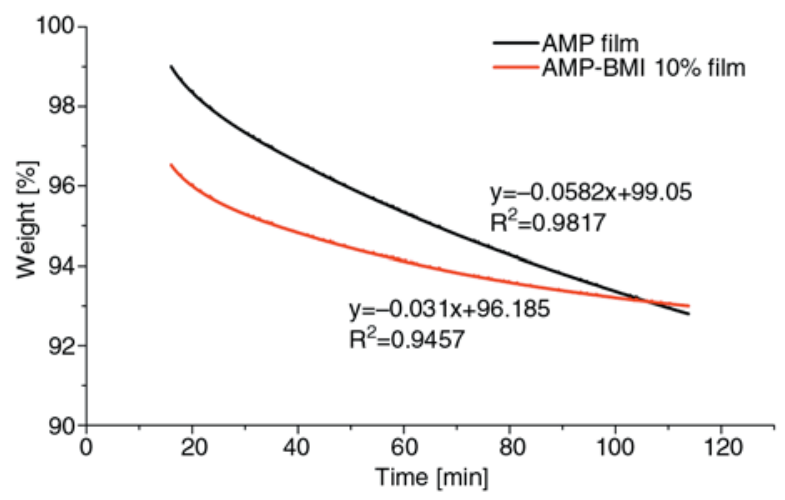

Figure 12. The isothermal TGA plot and calculation of degradation rate for the duration of thermal resistance: AMP and AMP-BMI10\% films at $300^{\circ} \mathrm{C}$

Table 5. Degradation results for AMP-BMI systems*

\begin{tabular}{|l|c|c|c|c|}
\hline \multicolumn{1}{|c|}{ Composite } & $\begin{array}{c}\mathbf{T}_{5 \%} \\
{\left[{ }^{\circ} \mathbf{C}\right]^{\mathbf{a}}}\end{array}$ & $\begin{array}{c}\mathbf{T}_{\max } \\
{\left[{ }^{\circ} \mathbf{C}\right]^{\mathbf{a}}}\end{array}$ & $\begin{array}{c}\mathbf{R} \\
{\left[\mathbf{\%}^{\circ}{ }^{\circ} \mathbf{C}\right]^{\mathbf{b}}}\end{array}$ & $\begin{array}{c}\mathbf{Y}_{\mathbf{c}} \mathbf{a t} \mathbf{7 0 0}^{\circ} \mathbf{C} \\
{\left[\mathbf{\%}^{\mathbf{c}}\right.}\end{array}$ \\
\hline AMP & 289.0 & 410.4 & 3.48 & 0.02 \\
\hline AMP-BMI 10\% & 263.2 & 434.2 & 2.58 & 8.23 \\
\hline AMP-BMI 20\% & 142.6 & 411.1 & 1.58 & 17.2 \\
\hline
\end{tabular}

*reported data is an average of 5 samples, the standard derivation is around

${ }^{2} 5^{\circ} \mathrm{C}$,

$\mathrm{b} 0.5 \%$,

$\mathrm{c} 1 \%$ 
The duration of the thermal stability was studied isothermally at $300^{\circ} \mathrm{C}$ for 100 minutes by using TGA. Figure 12 records the weight percent versus isothermal time. The curves show linear tendency, so we make a mathematical simulation of the relationship between weight and time by using a linear model. The results are listed as Equations (6) and (7):

$$
\begin{array}{ll}
y=-0.0582 x+99.05 & R^{2}=0.9817 \\
y=-0.031 x+96.185 & R^{2}=0.9457
\end{array}
$$

where $y$ is the weight percent, $x$ is the isothermal time. Equation (6) is for pure AMP film and Equation (7) is for AMP/BMI film. The slopes, representing the isothermal degradation rate, $0.0582 \mathrm{vs}$. $0.031 \% / \mathrm{min}$, indicate that BMI can slow down the degradation behavior. It is noted here that the simulation is only used to show the difference of thermal resistance between two materials, it doesn't refer to the degradation mechanism.

\section{Conclusions}

An initially liquid modified n-acryloylmorpholine/ BMI was developed which could be UV cured. The formulation exhibited higher reactivity under UV curing compared to conventional thermal curing. A free radical mechanism was proposed which was elucidated using the DPC and FTIR. The overall curing kinetics parameters, such as reaction rate coefficient, the order of initiation reaction, activation energy and frequency factor were calculated by using isothermal DPC method. The relationship between reaction rate and conversion was obtained from this study. The thermal stability of the new formulation was also shown to be improved over thermally cured systems, with the stability reaching as high as $400^{\circ} \mathrm{C}$; this was attributed to the significant increase in the BMI content for the system.

\section{References}

[1] Liu Y-L., Chen Y-J.: Novel thermosetting resins based on 4-(N-maleimidophenyl) glycidylether: II. Bismaleimides and polybismaleimides. Polymer, 45, 1797-1804 (2004).

[2] Meng J., Hu X, Boey F. Y. C., Li L.: Effect of layered nano-organosilicate on the gel point rheology of bismaleimide/diallylbisphenol A resin. Polymer, 46, 2766-2776 (2005).
[3] Boey F. Y. C., Song X. L., Yue C. Y., Zhao Q.: Effect of AlN fillers on the properties of a modified bismaleimide resin. Journal of Materials Processing Technology, 90, 437-439 (1999).

[4] Hu X., Fan J., Yue C. Y.: Rheological study of crosslinking and gelation in bismaleimide/cyanate ester interpenetrating polymer network. Journal of Applied Polymer Science, 80, 2437-2445 (2001).

[5] Fan J., Hu X., Yue C. Y.: Static and dynamic mechanical properties of modified bismaleimide and cyanate ester interpenetrating polymer networks. Journal of Applied Polymer Science, 88, 2000-2006 (2003).

[6] Fan J., Hu X., Yue C. Y.: Dielectric properties of selfcatalytic interpenetrating polymer network based on modified bismaleimide and cyanate ester resins. Journal of Polymer Science Part B: Polymer Physics, 41, 1123-1134 (2003).

[7] Meng J., Hu X., Boey F. Y. C., Li L.: Effect of layered nano-organosilicate on the gel point rheology of bismaleimide/diallylbisphenol A resin. Polymer, 46, 2766-2776 (2005).

[8] Boey F. Y. C., Santosh K. R.: Microwave radiation curing of polymers: Using a temperature equivalent method for cure reaction analysis. Advances in Polymer Technology, 19, 194-202 (2000).

[9] Chia H. L., Jacob J., Boey F. Y. C.: The microwave radiation effect on the polymerization of styrene. Journal of Polymer Science Part A: Polymer Chemistry, 34, 2087-2094 (1996).

[10] Boey F. Y. C., Yap B. H.: Microwave curing of an epoxy-amine system: effect of curing agent on the glass-transition temperature. Polymer Testing, 20, 837-845 (2001).

[11] Abadie M. J. M., Xiong Y., Boey F. Y. C.: UV photo curing of $N, N$ '-bismaleimido-4, 4'-diphenylmethane. European Polymer Journal, 39, 1243-1247 (2003).

[12] Boey F. Y. C., Rath S., Ng A. K., Abadie M. J. M.: Cationic UV cure kinetics for multifunctional epoxies. Journal of Applied Polymer Science, 86, 518-525 (2002).

[13] Decker C., Bianchi C., Morel F., Jönsson S., Hoyle C.: Mechanistic study of the light-induced copolymerization of maleimide/vinyl ether systems. Macromolecular Chemistry and Physics, 201, 1493-1503 (2000).

[14] Bongiovanni R., Sangermano M., Malucelli G., Priola A.: UV curing of photoinitiator-free systems containing bismaleimides and diacrylate resins: bulk and surface properties. Progress in Organic Coatings, 53, 46-49 (2005).

[15] Rao B. S.: Synthesis, characterization, and thermal stability of bismaleimides derived from maleimido benzoic acid. Journal of Polymer Science Part A: Polymer Chemistry, 27, 2509-2518 (1989).

[16] Giulio D., Gautier C. M., Jasse B.: Fourier transform infrared spectroscopic characterization of aromatic bismaleimide resin cure states. Journal of Applied Polymer Science, 29, 1771-1779 (1984). 
[17]Gu A. J. : High performance bismaleimide/cyanate ester hybrid polymer networks with excellent dielectric properties. Composites Science and Technology, 66, 1749-1755 (2006).

[18] Iijima T., Hayashi N., Oyama T., Tomoi M. : Modification of bismaleimide resin by soluble poly(ester imide) containing trimellitimide moieties. Polymer International, 53, 1417-1425 (2004).

[19] Abadie M. J. M., Chia N. K., Boey F. Y. C.: Cure kinetics for the ultraviolet cationic polymerization of cycloliphatic and diglycidyl ether of bisphenol-A (DGEBA) epoxy systems with sulfonium salt using an auto catalytic model. Journal of Applied Polymer Science, 86, 1587-1591 (2002).

[20] Boey F. Y. C., Chia N. K., Rath S. K., Abadie M. J. M., Gan G. K.: Low-energy electron beam-induced cationic polymerization with onium salts. Journal of Applied Polymer Science, 82, 3099-3108 (2001).

[21] Rath S. K., Boey F. Y. C., Abadie M. J. M.: Cationic electron-beam curing of a high-functionality epoxy: effect of post-curing on glass transition and conversion. Polymer International, 53, 857-862 (2004).

[22] Boey F. Y. C., Xiong Y., Rath S. K.: Glass-transition temperature in the curing process of bismaleimide modified with diallylbisphenol A. Journal of Applied Polymer Science, 91, 3244-3247 (2004).

[23] Boey F. Y. C., Song X., Rath S. K., Yue C. Y.: Cure reaction for modified diallylbisphenol A/diaminodiphenylsulfone/bismaleimide. Journal of Applied Polymer Science, 85, 227-235 (2002).

[24] Boey F. Y. C., Qiang W.: Experimental modeling of the cure kinetics of an epoxy-hexaanhydro-4methylphthalicanhydride (MHHPA) system. Polymer, 41, 2081-2094 (2000).
[25] Boey F. Y. C., Song X. L., Yue C. Y., Zhao Q.: Modeling the curing kinetics for a modified bismaleimide resin. Journal of Polymer Science Part A: Polymer Chemistry, 38, 907-913 (2000).

[26] Boey F. Y. C., Qiang W.: Glass-transition temperature-conversion relationship for an epoxy-hexahydro4-methylphthalic anhydride system. Journal of Applied Polymer Science, 78, 511-516 (2000).

[27] Decker C., Bianchi C., Jönsson S.: Light-induced crosslinking polymerization of a novel N-substituted bis-maleimide monomer. Polymer, 45, 5803-5811 (2004).

[28] Morel F., Decker C., Jönsson S., Clark S. C., Hoyle C. E.: Kinetic study of the photo-induced copolymerization of N-substituted maleimides with electron donor monomers. Polymer, 40, 2447-2454 (1999).

[29] D’ Agosto F., Charreyre M., Veron L., Lauro M., Pichot C.: Kinetic study of free-radical solution copoly-merization of $\mathrm{N}$-acryloylmorpholine with an activated ester-type monomer, $\mathrm{N}$-acryloxysuccinimide. Macromolecular Chemistry and Physics, 202, 1689-1699 (2001)

[30] Boey F. Y. C., Qiang W.: Determining the gel point for an epoxy-hexaanhydro-4-methylphthalic anhydride (MHHPA) system. Journal of Applied Polymer Science, 76, 1248-1256 (2000).

[31] Pappas S. P.: Radiation curing: science and technology. Plenum Press, New York (1992).

[32] Xiong Y., Boey F. Y. C., Rath S. K.: Kinetic study of the curing behavior of bismaleimide modified with diallylbisphenol A. Journal of Applied Polymer Science, 90, 2229-2240 (2003). 